406 Revista Ius et Praxis - año 14 - n 1

Twining, William.

RETHINKING EVIDENCE. EXPLORATORY ESSAYS

Recensión de Claudio Meneses Pacheco

páginas 407 - 409

\title{
RETHINKING EVIDENCE. EXPLORATORY ESSAYS
}

\author{
Twining, William, Cambridge University Press, segunda edición, Cambridge, 2006, \\ $511 \mathrm{p}$.
}

Claudio Meneses Pacheco*

La publicación de la segunda edición de este libro es una noticia que merece divulgarse en nuestro medio, donde escasean los trabajos históricos y teóricos sobre la prueba judicial. Especialmente interesante es el enfoque dado por su autor, quien en un total de 15 ensayos redactados durante veinticinco años de actividad académica, se encarga de destacar el carácter multidisciplinario que presenta el fenómeno de las pruebas procesales, lo que -como diremos al final- tiene importantes repercusiones en la concepción del Derecho probatorio.

William Twining es profesor emérito de Derecho de la University College London. Con un conjunto de investigaciones sobre la problemática de la prueba en juicio, distribuidas entre libros y artículos, ha podido profundizar complejas cuestiones de esta área del Derecho, en especial las concernientes al ámbito de aplicación del law of evidence y las referidas al razonamiento en el establecimiento judicial de los hechos. En este último aspecto, sus aportes han recibido un reconocimiento especial en la ciencia jurídica anglosajona, como lo evidencian los comentarios formulados por Neil MacCormick en una entrevista publicada hace un par de años (Doxa. Cuadernos de Filosofía del Derecho, Universidad de Alicante, Alicante, №29, 2006, p. 488). En la doctrina de civil law, los libros de mayor peso demuestran cómo sus contribuciones también son relevantes para los países con sistemas de enjuiciamiento de base romano-canónica o germánica. Así puede verse, junto a otros, en los textos de Michele Taruffo (cfr. por todos, La prueba de los hechos, trad. J. Ferrer Bertrán, Trotta, Madrid, 2002), y en el reciente trabajo de Jordi Ferrer Beltrán sobre valoración probatoria (cfr. La valoración racional de la prueba, Marcial Pons, Madrid, 2007)

Profesor de Derecho Procesal, Universidad de Valparaíso. Becario del Programa de Doctorado, Universidad de los Andes, Chile. Correo electrónico: Claudio.meneses@uv.cl.

Revista Ius et Praxis - año 14 - n 1407

\section{Recensión de Claudio Meneses Pacheco}

Donde no ha existido la difusión necesaria de los trabajos de Twining es en el círculo de investigaciones nacionales, dentro del cual -salvo contadas excepciones- sus aportes son prácticamente ignorados. Ello nos motiva a propagar el aparecimiento de este importante libro, que nos invita nada menos que a repensar cruciales tópicos de la prueba judicial.

Una de las ideas base de los ensayos dice relación con el carácter multidisciplinario al que aludimos al principio. Sin ir más lejos, es el tema con el cual finaliza el libro, con un artículo titulado precisamente "Evidence as a multi-disciplinary subject' (pp. 436-456). Básicamente, lo que sostiene el autor es que los problemas del Derecho probatorio (law of evidence) están íntimamente relacionados con el manejo de la prueba en otras disciplinas académicas y en otras formas de adopción de decisiones prácticas. De este planteamiento central surgen una serie de precisiones, en cuanto -por ejemplo- al propio concepto de "evidence"; al modo de llevar a cabo el razonamiento inferencial en el campo de los hechos; al uso del sentido común y, al empleo de la narrativa.

Los 15 artículos abordan principalmente asuntos de historia del modelo de law of evidence (capítulos 3,6 y 7); cuestiones sobre razonamiento y argumentación en la determinación judicial de la materia fáctica (capítulos 2, 4, 8, 12, 13 y 14); las perspectivas holistas y atomistas, con referencias a las "lawyers'stories"' (capítulos 9, 10 y 11). Una mirada general del cuadro teórico del autor aparece expuesta en el primer capítulo, donde está sintetizada la historia de la gestación de estos estudios. 
Uno de los temas que más debiera llamarnos la atención dice relación con la concepción del Derecho probatorio (law of evidence). Las explicaciones de Twining descansan en la idea del carácter residual de las normas jurídicas en el tratamiento de las probanzas procesales, las que -según su parecer- deben ser abordadas en primer término por directrices provenientes de otras áreas del quehacer humano. Antes que las reglas de Derecho, corresponde aplicar criterios epistemológicos, lógicos o probabilísticos, haciendo uso además de la información que proviene de la ciencia, la psicología o la medicina. Como ya lo hemos dicho, esto aparece reforzado en el capítulo 15, en el que el autor enfatiza cómo las otras disciplinas repercuten directamente en el tratamiento de los hechos en las causas judiciales. Acaso la forma más gráfica de citar el pensamiento del autor sobre el particular, sea la metáfora con la cual él describe la situación del law of evidence en relación con la regulación de las pruebas. Subrayando, en efecto, su carácter complementario, lo compara con el "queso gruyere", donde el queso vendría a ser el Derecho probatorio y los agujeros aquellas materias no reguladas por éste, de modo tal que -en realidad- es posible encontrar más hoyos que queso (cfr. capítulo 6, "What is the Law of Evidence?", pp. 210-218).

408 Revista Ius et Praxis - año 14 - n 1

Twining, William. RETHINKING EVIDENCE. EXPLORATORY ESSAYS

Nos quedamos con esta última metáfora para exhortar a la lectura de este importante texto histórico y teórico. En un medio tan legalista como el nuestro, una explicación como la precitada nos debe hacer reflexionar seriamente ("repensar") en torno al rol que efectivamente tienen las normas jurídicas en la determinación de la quaestio facti. Por nuestra parte, nos inclinamos por una visión como la propuesta en el libro que es materia de esta recensión. 